\title{
A Research into the Design Strategies for Public Seating in a Windy Environment
}

\author{
Ding Zhou \\ School of Industrial Design \\ Nanjing University of the Arts \\ Nanjing, China \\ e-mail: zhoudingshanshan@gmail.com
}

\author{
Yuqing Zou \\ School of Industrial Design \\ Nanjing University of the Arts \\ Nanjing, China \\ e-mail: zou-yuqing@126.com
}

\author{
Jiabei Jiang \\ School of Industrial Design \\ Nanjing University of the Arts \\ Nanjing, China \\ e-mail: Jiangjb1015@hotmail.com
}

\begin{abstract}
Public seating, as one of the most important urban infrastructures, has been widely installed throughout cities. Little prior research has paid attention to the influence of the natural environment on public seating services and citizens. Based on quantitative data collection statistics from public seating occupancy in a specific windy environment, and user-centred behavioural observations and interviews, this research generated results in the form of charts, texts and images. Based on the findings of this research, design strategies for public seating in seaside windy environment can be deduced, aimed at creating high levels of comfort and satisfaction for the public.
\end{abstract}

Keywords-public seating; design strategies; windy environment; human comfort and satisfactions

\section{INTRODUCTION}

Public seating, which falls under the recreational service category of city furniture, significantly determines the quality of city space [1]. Seating not only plays an important role as a social networking site but also supplies users an opportunity to observe and experience the public space constituted by people, appliance and architecture. Additionally, public seating displays human caring as it serves vulnerable groups such as homeless in a city because it is free to use [1].

In the rapid development of urban construction, worldwide societies and governments have realized the importance of city furniture. Therefore, a considerable number of studies focusing on diverse fields of city furniture design have been done. Yücel analyses a range of systemic design elements of street furniture, including safety, materials, colour, sustainability, location, etc. [2] Based on the social attributes of public seating, Lee, Chan and Tang study users' characteristics and behaviours via qualitative researches. They finally concluded that the inclusive design strategies that aim to satisfy the needs of citizens' interaction [3]. Employing aesthetic theory, Shan and $\mathrm{Xu}$ suggest that the visual design for street furniture could promote a city's image and culture [4]. Despite their abundant research in diverse fields, those studies mainly contributed to the enhancement of comfort and pleasure for citizens using public seating.

However, prior public seating researches, which paid attention to humans, city furniture, and the social environment, have neglected the relationship between users and nature, the objective use of the environment. Thanks to the comfortable temperature and charming scenery, coastal cities have become extremely popular tourist destinations. An analysis of human body comfort index of 20 tourist cities in China reports, "Under the similar latitudinal conditions, the comfortable month and days were more in coastal tourist cities than in inland tourist cities" [5]. In the Global livability ranking and report of The Economist 2013, there were seven coastal cities that rank in the top ten. In 2014, a report showed that the top nine most livable cities in China included five coastal cities. However, those attractive cities usually suffer from windy environment created by either atmospheric circulation on earth's surface or sea breeze, a gentle wind that develops over bodies of water near land due to differences in air pressure created by their different heat capacity. Therefore, the prior research's failure to incorporate the natural environment and user into the design may lead to both design strategy homogenization and non-user-friendly products.

\section{RESEARCH OBJECTIVES}

The purpose of this research is to produce effective design strategies for public seating impacted by windy environments in coastal cities, so as to increase human body comfort and satisfactions for passers, tourists, citizens, etc. In addition, this research's findings are able to guide public seating manufacturers in developing competitive products as well as providing people-oriented criteria for the related city departments. What's more, it could inspire designers and 
scholars who focus on the design of city furniture to pay attention to creating a harmonious relationship among users, city furniture, social environment and natural environment.

\section{RESEARCH METHODS}

\section{A. Research Setting and Objects}

In order to obtain the effective data and materials, the setting of this research was built on two standards. First, the natural environment for study should exist in a typical coastal city that is frequently impacted by wind. Second, the specific context should be a popular space of that city, where considerable people flow in and out and public seating exists.

According to above standards, as shown in "Fig. 1" , this research selected a leisure square located in northeast of the Te Papa, which is known as the National Museum of New Zealand and located in Wellington, the capital city of this country. First and foremost, Wellington is a typical windy coastal city. The local natural environment is created by not only general atmospheric circulation on earth's surface and sea breeze but also its special geographical location and terrain. The city's location, which is close to the mouth of the narrow Cook Strait, leads to its vulnerability to strong gales as well as its nickname of Windy Wellington. A report of New Zealand's national climate database showed that the monthly average wind speed in Wellington has reached force three on the Beaufort scale during the past ten years since 2004. Even more, the wind speed can reach force four during the months of September, October and November. Secondly, National Museum of New Zealand is one of the most famous and popular tourist attractions in Wellington downtown. In its northwest leisure square that faces the picturesque harbour, a lot of public seating has been installed in this ideal recreation space for a large number of visitors, tourists, citizens, etc.

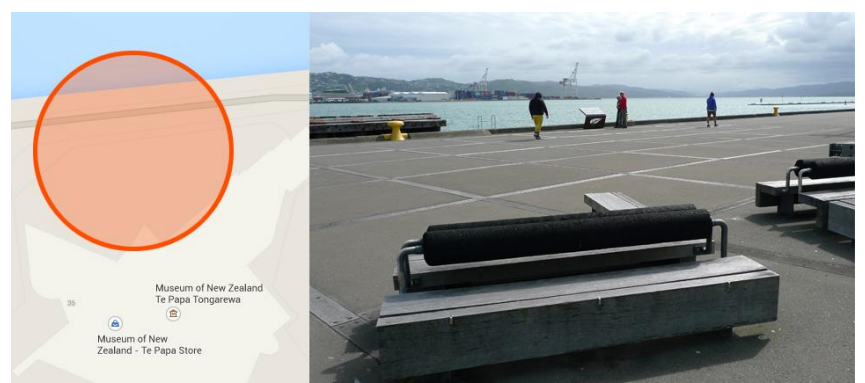

Fig.1. Northwest square of the National Museum of New Zealand.

In addition, this research sets the eight sets of public seating located in the above mentioned place as specific context for observation. Due to the reasonable comfort and broad perspective, these seats in "Fig. 2" could attract a considerable number of users, who brought enough data and materials for this study.

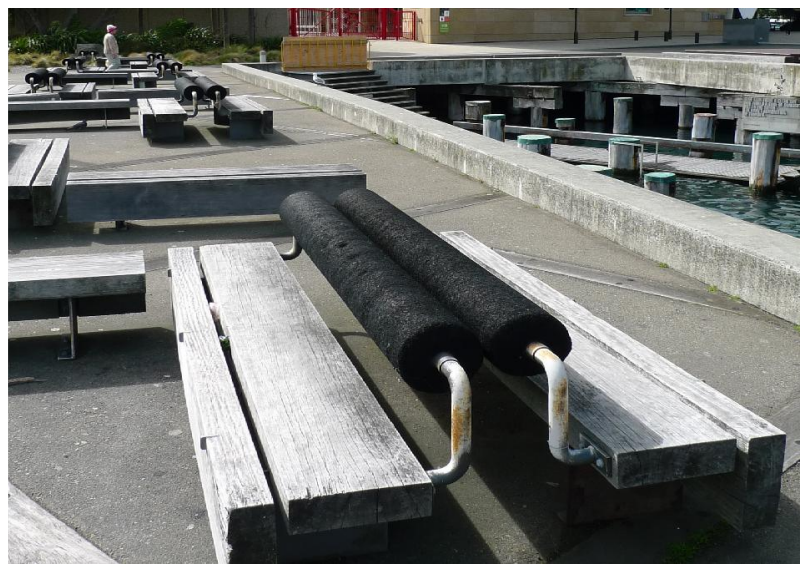

Fig.2. Eight sets public seating in the square.

\section{B. Quantitative Data Collection and Statistics for the Occupancy of Public Seating}

The change of wind speed causes the fluctuation of the occupancy of public seating. The collected data revealed the relation among human, city furniture and natural environment, as well as how wind impacts the usage of public seating.

In order to obtain effective quantitative data, this research strictly controls the conditions of data collection. Many scholars agree that a person's outdoor behaviours depends on the person's comfort, which is influenced by a range of elements, including wind, temperature, solar radiation, relative humidity, etc. However, it is debatable which of these factors has the greatest influence. Some investigation indicated, at a constant temperature, wind plays a more important role than the other two in determining human body comfort. Additionally, another group of researchers pointed out that three elements work almost equally [6]. Some researchers also suggested that wind influence was greatly weakened on rainy days because people excluded outdoor activities [7]. Therefore, to avoid possible interference, this research collected more than 20 recordings of the real-time wind speed when other weather factors performed similarly. It also recorded the corresponding occupancy of public seating. MetService, a New Zealand based weather company located in Wellington, released the wind speed used in this study.

This research produced a scatter plot and logarithmic trendline, which reflected the connection between wind speed and the occupancy of public seating. Meanwhile, based on the average occupancy of seating in each Beaufort wind force scale, the study created a column chart to compare users' willingness to use public seating in varying wind environments.

\section{User-Centred Behavioural Observations and Interviews}

User-centred behavioural observations and interviews could reflect users' specific experiences and need in a variety of wind environments.

In order to obtain rich materials for qualitative research, this research recorded the images of users stretch gestures, individual behaviours, social behaviours, etc., which 
corresponded to the relevant wind speed. Additionally, random interviews with users (including self-reported comfort, real-time experiences in the wind, open discussions, etc.) were recorded in audios and text.

According to the recording conditions of the wind speed in each single Beaufort wind force scale, the above materials were classified into several groups. Through a visualization of information, research results aimed to discover users' common behaviours and requirements as well as their psychological feedback when they sat in different wind speed conditions. Simultaneously, users' personalized viewpoints were also explored as reasonable materials.

\section{RESEARCH RESULTS AND FINDINGS}

\section{A. Results and Findings of the Quantitative Data Collection and Statistics}

From 15 November to 7 December in 2014, this research collected relevant data in predetermined weather conditions. Based on that data, statistical results were generated. There was a clear inverse relationship between wind speed and occupancy of public seating. Force scale also influences public seating occupancy. Users tended to sit in an environment where the wind of force was three or below. A wind speed higher than $25 \mathrm{~km} / \mathrm{h}$ decreased users' willingness to use the seating.

"Fig. 3" shows a scatter plot and logarithmic trend line. All nonzero occupancy of public seating exist within a range of windy environment when wind speed was less than 25 $\mathrm{km} / \mathrm{h}$. Five of the top six highest number of occupancy listing from four to eight were in the wind speed condition of $20 \mathrm{~km} / \mathrm{h}$ and below. When the wind speed increased, logarithmic trend line illustrated that the occupancy of public seating significantly decreased.

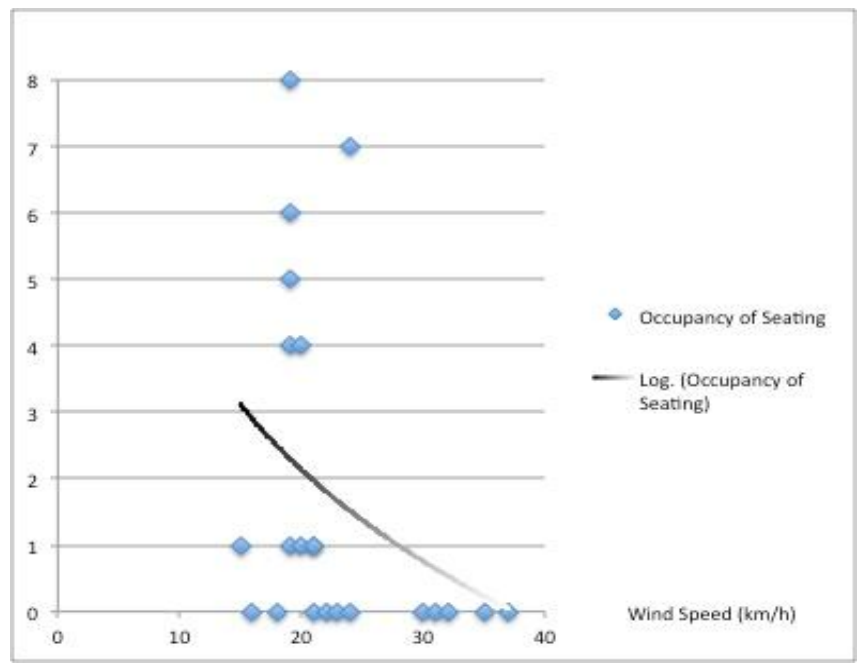

Fig.3. Scatter plot and logarithmic trend line of the connection between wind speed and occupancy of seating.

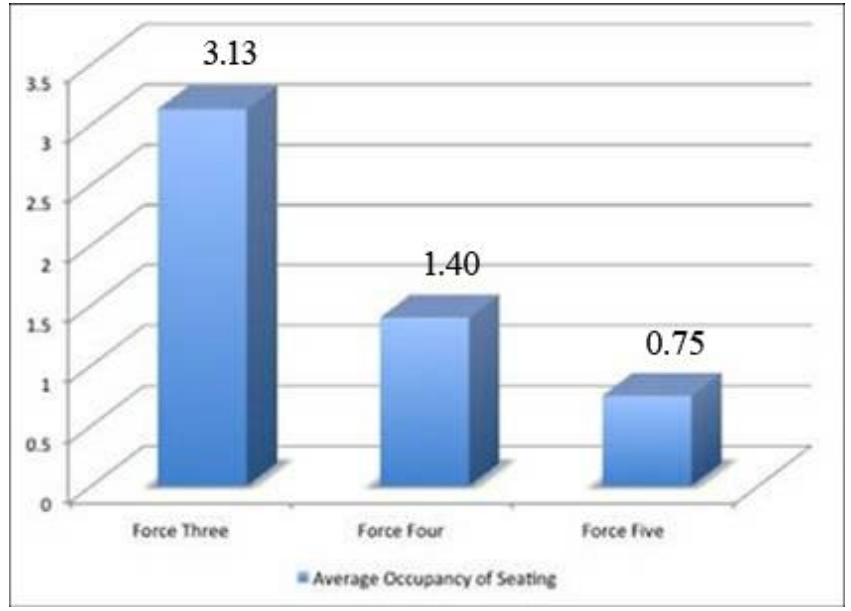

Fig.4. Column chart of average occupancy of seating in each wind force scale.

"Fig. 4" is a column chart showing the average occupancy of seating in each wind force scale. The Beaufort wind force scale defines the wind in $13-19 \mathrm{~km} / \mathrm{h}$ as force three, while wind speed of $20-30 \mathrm{~km} / \mathrm{h}$ and $31-40 \mathrm{~km} / \mathrm{h}$ are respectively named as force four and five. The average occupancy during a wind force of three is 3.13 , which is obviously higher than the average occupancy of 1.4 in force four and 0.75 in force five.

\section{B. Results and Findings of the User-Centred Behavioural Observations and Interviews}

All materials of user-centred behavioural observations and interviews were classified into several groups based on the wind force scales. Normally, users feel comfortable in wind force three and below. The less windy environment enables users to enjoy recreational activities, like reading books, surfing the internet from smart phones and so on. Also, a wind of force four and above not only reduces people's satisfactions and comfort but also creates inconvenience and noise. Furthermore, a highly windy environment disturbs users' recreation and weakens their desire for seating.

As displayed in the Fig. 5, users acted comfortably in a series of casual gestures in the wind force three. While enjoying the scenery, almost all users performed one or another additional behaviours, such as reading books, listening to music through earphones, surfing the Internet from mobile phones, etc. Couples, families and other groups seemed to be relaxed and happy. Most of the time, users basically reported that they felt very comfortable and cosy at wind force three.

But, at wind force four, both the single users and group participators acted differently. Thei behavior changed to include actions such as putting their hands in their pockets or wearing a hat for warmth. In addition, users' sitting durations at wind force four were much shorter than that in force three. No users appeared in the windy environment of force five. Users also mentioned a chilly feeling; especially after the wind had reached force four, most users described that they felt cold and uncomfortable. Additionally, earphone users 
complained that wind created an annoying noise that interfered with their music. Moreover, several citizens and visiting staff who had worked in Wellington for a long period provided similar experience that an uncomfortable windy environment made them leave much earlier on a sunny day than their initial plan.
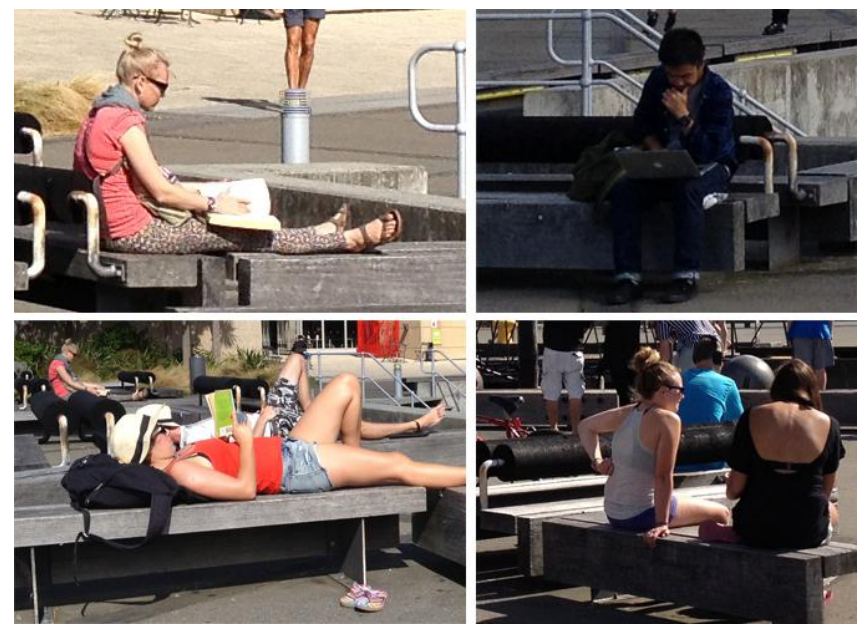

Fig.5. Users' behaviours in a windy environment of force three.

\section{CONClusions AND DESIGN STRATEgIES}

Based on the findings generated from quantitative data collection and statistics analysis as well as user-centred behavioural observations and interviews, this research deduces six design strategies for public seating impacted by windy environment in coastal city, aiming at effectively increasing reasonable human comfort and satisfactions.

First, public seating and its facilities should effectively block wind coming from the exterior environment and control it within force three of the Beaufort wind force scale. Second, public seating and its facilities should provide users a broad field of vision for enjoying the scenery. Thirdly, public seating and its facilities should provide users with enough space for their casual gestures. Fourth, public seating and its facilities should assist users in their recreations, such as reading books, surfing Internet, listening to music, etc. Fifth, public seating and its facilities should effectively reduce the noise created by wind for music enthusiasts. Sixth, including wind, temperature, solar radiation, relative humidity, etc., a range of elements that affect human comfort and satisfactions should be involved in the design for public seating impacted by windy environment.

\section{ACKNOWLEDGMENT}

This article is a part of a research project of Nanjing University of the Arts. The number of this project is XJ2013019. China Scholarship Council and Victoria University of Wellington's School of Design importantly supported the research for this article during the period when Ding Zhou, the lead author, worked as a visiting scholar in New Zealand. He also gratefully thanks Dr. Xiaodan Gao, a senior learning adviser at Victoria University of Wellington, for her tutorial of academic writing and modification for the article.

\section{REFERENCES}

[1] G. Perrem, "The Importance of Seating in Local Public Space," Building Material, No. 18, global / local (spring 2009), pp. 70-71.

[2] G F. Yücel, "Street Furniture and Amenities: Designing the User-Oriented Urban Landscape," 2013.

[3] Y H B. Lee, L H. Chan, M. Tang, "Park Seating Furniture Design in Hong Kong: A Case Study of Inclusive Design and Its Relation to User Interaction," 2013.

[4] H. Shao, B. Xu, "Research on integral design and innovation of street furniture in Hangzhou," Computer-Aided Industrial Design \& Conceptual Design (CAIDCD), 2010 IEEE 11th International Conference on. IEEE, 2010, 1: 401-403.

[5] Q. Bai, Z. Huo, N. He, N. Li, N. Wei, "Analysis of Human Body Comfort Index of 20 Tourist Cities in China," Chinese Journal of Ecology, 2009, 28(8): 1607-1612.

[6] N. Metje, M. Sterling, C J. Baker, "Pedestrian comfort using clothing values and body temperatures," Journal of Wind Engineering and Industrial Aerodynamics, 2008, 96(4): 412-435.

[7] T. Stathopoulos, "Pedestrian level winds and outdoor human comfort," Journal of wind engineering and industrial aerodynamics, 2006, 94(11): 769-780. 